\title{
CARDIOVASCULAR DEPRESSION FOLLOWING MAJOR VAGINAL SURGERY
}

\section{H. BARRIE FAIRLEY, M B., B.S., F.F.A.R C.S. ${ }^{*}$}

THIS PAPER presents a series of 176 unselected cases of major vaginal surgery (1.e., vaginal hysterectomies, reparrs, and other plastic procedures) as a basis for a discussion of the factors relating to the aetiology and logical therapy of hypotension following this type of surgery

With the exception of four cases, all the anaesthetics have been given by members of the attending staff of the Toronto General Hospital and the surgery was performed by their gynaecological colleagues. The four cases mentioned were included since the anaesthetics were given by fully certificated anaesthetists The work is that of 'seventeen different anaesthetısts.

All the patients have been through the T G.H. Private Patients' Recovery Room and, in the main, my figures are taken from the records made durng their postoperative stay there (Percentages will be quoted to the nearest unit.)

It was first established that postoperative hypotension is unusually common in this group. Defining, empurically, hypotension as a systolic pressure of $90 \mathrm{~mm}$ $\mathrm{Hg}$., or less, at any time in the recovery period, it was found that 101 cases (57 per cent) came under this heading. It should be mentioned that even more patients might have been added to the hypotensive group but for the fact that 23 of the cases, in the non-hypotensive group, had been given either pressor agents ( 11 per cent of the whole senes) or blood ( 2 per cent of the whole senes) as a prophylactic measure during the operative procedure. A recent series of 500 consecutive cases of all types of surgery, passing through the same recovery room, showed only 10 per cent to register systolic blood pressures below $90 \mathrm{~mm} \mathrm{Hg}$. It is evident, therefore, that hypotension is unusually prevalent following major vaginal surgery-a tact already well known to many

\section{Causes of Hypotensiov}

An attempt was made to consider the possible causes of this problem and to assess the extent of the contribution of each factor These will be discussed in turn

\section{Blood Loss}

This is not unusually gross during this type of procedure Some surgeons reduce the volume by the injection of a solution containing adrenaline, with or without Procaine HCL. Those cases in which the blood loss seems considerable receive adequate replacement therapy as the occasion demands

Perusal of the records in this series showed that this was unlikely to be a major factor. Of those who became hypotensive, 78 ( 77 per cent) had a relative bradycardia i e, a normal or below-normal heart rate. This is not the picture which we are accustomed to see in haemorrhagic shock. Additionally, the fall in

-Department of Anaesthesia, Unıversity of Toronto and Toronto General Hospital 
blood pressure rarely occurred durng the operation when blood loss would occur.

\section{Alteration in Posture}

It is reasonable to suppose that, since most of the cases in this series developed hypotension after the operation had finished, the fall in blood pressure might be due to a peripheral displacement of blood to the legs following their return from a prolonged elevation in lithotomy stirrups. This possibility meits careful examination since, if it is a major contributory factor, the treatment is simple, 1.e., raising the foot of the bed after operation.

It is well known that the lower limbs are capable of holding a considerable, and variable, volume of blood Saunders ( 1 ) has made use of this in his negative pressure method of acheving controlled hypotension and we have all used the anti-Trendelenburg position in an attempt to reduce blood loss during head and neck surgery. Bearing in mind the fact that one has mitially added to the circulating blood volume (relative to the functional vascular bed) by raising the legs into the lithotomy position, at a time when the patient has just had her vasomotor tone insulted by the induction of anaesthesia, one wonders why the same volume of blood should not be returned whence it came, when the legs are lowered, and the circulatory status quo return to normal. One must consider the factors influencing venous return.

(a) Gravity This is probably only of minor importance here since the legs are not lowered below horizontal and water, and therefore blood, finds its own level.

(b) Muscular support. Since 55 ( 55 per cent) of the hypotensive cases did not sustain a fall in arterial pressure untal the return of consciousness (and, therefore, of muscular tone) it would seem illogical to incriminate the lack of muscular support as a major aetiological factor

(c) The thoracic pump mechanism The same argument applies here. While the patient is in lithotomy position, her respirations would be less efficient Case and Strles (2) have shown that the vstal capacity is reduced to 82 per cent of normal in this position and one may assume that the intra-abdomiral pressure is raised Yet $_{n}$ the hypotension occurred when this sad state of affarrs had been relieved.

(d) The residue of mean aortic pressure, once this has traversed the arteriolar and capillary beds In this series, the pressure remained constant during the operation

Of more importance are the factors influencing the size of the vascular bed in the legs. If the capacity of this is increased, then this change of posture becomes of probable significance. These factors are:

(a) Vascular tone. Cushny (3) has shown, by plethysmograph studies, that blood flow through the limbs is markedly increased under anaesihesia, even though the arterial pressure remains constant Pappenheimer and Soto-Rivera (4) have demonstrated that the flow in the hind limbs is proportional to the femoral artery pressure minus the femoral vein pressure. It follows, therefore, that if the flow is increased without a rise in arterial pressure (and such a rise is 
not recorded in this series) the raised flow must be related to a fall in the venous pressure and return However, this indilgence in theory has merely shown that, when an anaesthetic is given, the peripheral vessels tend to dilate and the venous return to fall. Compensation is normally adequate and occurs as tollows. The cardiac output is dependent upon the venous return. With dilated peripheral vessels, a reduced cardiac output results in a fall in arterial pressure which, in accordance with Marey's Law, supplies the necessary reflex compensating tachycardia or, simply a fall in venous return results in a rise in heart rate.

(b) $\mathrm{pH}$ changes peripherally. An increase in acidity will result in a vasodılatation. There is no adequate reason to suppose that the $\mathrm{pH}$ falls in the lithotomy position, in the lower limbs. The arterial pressure was maintamed, in all cases in this series, while the legs were rased and removal of metabolites should have been maintained throughout. Again, a fall in $\mathrm{pH}$ should cause a tachycardia.

(c) The venular pump mechanism. This has been described by Primrose (5), who suggests that successive contractions in the minute vessels of the venous system produce a propulsive force This is not universally accepted but, since the fall in arterial pressure seems to be related to the return of consciousness, there is no reason for assuming that this mechanism should become deficient at this particular stage.

If the fall in venous return resulting from dropping the legs to the horizontal is the main cause of our hypotension, a tachycardıa should be evident. This only occurred in 11 ( 11 per cent) of hypotensive cases (The fact that only 89 ( 88 per cent) hypotensives have been accounted for is due to the difficulty of deciding what degree of increase in rate is reasonable for a given fall in arterial pressure A small group, therefore, did not show any significant change in rate)

It is unlikely that venous return is deficient m many of these cases, as a primary factor In 38 hypotensives, it was possible to observe the effect of elevating the foot of the bed, without the confusing influence of other therapy. In 30 ( 78 per cent) of these cases there was no umprovement Venous pressure studies might be an interesting way of confirming this point

We return now to the other possible causes of hypotension

3. Prolonged Operating Time, Rough Handling of the Patient, Heat and Electrolyte Imbalance

These factors are grouped together and it is not proposed to discuss them other than to say that they seem of little importance in this series

\section{Carbon Dioxide Accumulation}

The respiratory embarrassment caused by the lithotomy position has been mentioned already and it is possible that this might be a contributory factor Many of the anaesthetists used small doses of muscle relaxants and spontaneous respiration through soda-lime, as part of their technique, and one would imagine that this might cause deficient ventilation. However, these cases showed no signs of carbon dioxide accumulation during the operation. In 109 cases ( 62 per cent of the whole series) the patients received relaxants. Of these, 63 (58 per cent) became hypotensive after operation. In 67 cases the patients did not receive relaxants and, of these, 38 (57 per cent) became hypotensive. The use 
of relaxants seems, therefore, neither to have contributed to, nor protected against, the occurrence of postoperative hypotension. Nevertheless, one feels that the use of relaxants with spontaneous respiration, in this position, requires close examination.

\section{Anoxia due to Elimination of $\mathrm{N}_{2} \mathrm{O}$}

Fink (6) recently showed the danger of anoxia occurring owing to the dilutuon of alveolar oxygen by expired $\mathrm{N}_{2} \mathrm{O}$, if the patient is allowed to breathe air at the end of an anaesthetic sequence utilizing this agent. He recommends that 100 per cent oxygen be given for a short period to tide the patient over this phase in his recovery. In this series, hypotension was only occasionally an immediate postoperative problem and did not respond to the routme use of oxygen therapy in the recovery room Thus, this does not seem to be an important tactor.

We are left with the two main causes of our hypotension.

\section{Pain}

This is a classical cause of hypotension and requires little elaboration. One knows that this region under discussion is well supplied with afferent fibres and that vaginal repairs rank in the forefront of painful operations. It would be reasonable to suppose that, if pain is a major contributory factor, a large group of the hypotensives would sustain a fall in arterial pressure as consciousness returns, or soon afterwards. Of the hypotensive group 55 ( 55 per cent) were conscious before the pressure fell Administration of an analgesic should result in a rise in pressure Unfortunately, this has not been the common practice, vasopressors being preferred. However, 12 (12 per cent) of the hypotensives improved following the administration of an analgesic. It is significant, though, that 7 ( 7 per cent) showed a fall in arterial pressure, and only entered the hypotensive group following their analgesic Only one patient received a barbiturate-I.V analgesic $-\mathrm{N}_{2} \mathrm{O}-\mathrm{O}_{2}$ sequence She maintamed a normal pressure after operation.

\section{Pelvi-Cardiac Reflex}

From what has preceded, it is evident that many possible causes of hypotension exist, with this type of surgery, but there is still a significant group unaccounted for

As mentioned earlier, 78 ( 77 per cent) of the hypotensives had a relative or absolute bradycardia. Systolıc pressures ranged between 40 and $90 \mathrm{~mm} \mathrm{Hg}$. and heart rates between $45-85 / \mathrm{min}$. Hast states (7) that a slow heart rate, associated with a fall in arterial pressure, may be assumed to be cause and effect and probably to be a variation of the vaso-vagal theme. Certainly, the causes of hypotension, discussed earlier, are all a'ssociated with a tachycardia Eurstein (8) has described the reflex arising from the pelvic nerves' endings on the afferent side and producing an increase in vagal tone on the efferent side, it seems, in this series, that this should be considered to be the major single factor in the incidence of the postoperative hypotension. That the reflex is related to the return of consciousness, in many cases, may be only coincidence although, by that time, the vagal blockıng effect of premedication and any autonomic blocking effect of the anaesthesia will have worn off. 
Treatment

Assuming that the intravenous therapy has been managed correctly and that oxygen therapy, control of the arrway, and elevation of the foot of the bed have been instituted, a persistent hypotension may be assumed to be due to stimul urising from the operative site The reflex may be broken at various levels:

1. Peripherally, on the afferent side Long-acting local anaesthetics injected at the operative site or long-acting regional anaesthesia could possibly be of prophylactic value The only local anaesthetic injected locally, in this series, was Procaine $\mathrm{HCl}$ In all cases, this would have been eliminated by the end of the operation It is of interest that, despite the lack of satisfactory results, 161 (92 per cent) of the whole series recelved barbiturate- $\mathrm{N}_{3} \mathrm{O}-\mathrm{O}_{2}$, or a similas sequence with relaxant added. No patients received epidural anaesthesia. Sufficiently longacting drugs, used by this route, might tide the patient over the autonomically unstable recovery perıod

2. Central depression. The possible value of giving analgesics earlier and more trequently than at present has been mentioned. Variation of the general anaesthetic technique has not been adequate, in this series, to assess the relative values of the various agents. There is no reason to suppose that one agent is any better than another, given the same degree of depression and adequate ventilation The possible blecking value of the misnamed hibernation technique might be recommended by some. Five patients recelved these drugs with or without barbiturate Four came into the hypotensive group, two with obvious bradycardia

3. Peripherally, on the efferent side No patients, in this series, received intravenous atropine as a form of treatment In the presence of obvious bradycardia, this is the therapeutic agent of choice, its vagal blocking effect being well established.

Inglis (9) has divided hypotension into three groups, according to whether there is fast, normal, or slow heart-rate It appears that we are dealing with his last group, in 77 per cent of cases. Certanly, in the 46 (46 per cent) of the hypotensives who were still unconscious, atropine gr $1 / 100 \mathrm{IV}$ would have been the therapy of choice for those with relative bradycardia

\section{Ganglion-blocking Agents}

If one assumes that the essential problem is that of a harmful reflex, which is mediated through the autonomic nervous system, and which becomes active during the recovery period, it might appear logical to use prophylactic treatment directed specifically at the autonomic ganglia. Most anaesthetists will agree that this problem is not of sufficient import to justify the use of a methonium compound or a thiophanium derivative in this connection. However, the value of intravenous procaine or lignocaine as part of the anaesthetic sequence merits consideration Unfortunately, this serıes does not include any cases for which this technique was used

\section{The Use of VAsopressor Agents}

From the practical standpoint, hypotension frequently responds to vasopressors and did so in 50 ( 50 per cent) of the hypotensive group. This is, essentially, symptomatic treatment and there are those who feel that this type of therapy, 
not based on aetology, is to be deprecated except in dire emergency (10). However, consideration of some of the agents used may be of value:

1. Methylamphetamme (Methedrine) This was the most popular of the pressor agents used. It has a prolonged action, stımulating both myocardium and peripheral vasculature However, the undesirable feature of this drug $s$ its cerebral stımulatory action, which produces postoperative restlessness. It may be used as an intravenous infusion but is less controllable, when given thus, than is nor-adrenaline. Overdosage results in piolonged hypertension.

2 L-nor-adrenaline (Levophed) $(11,12,13)$. This is considered to be the physiologically active portion of adrenalne with respect to peripheral vasoconstriction Goldenberg, Apgar, Deterling and Pines (11) were the first to publish the therapeutic effects of this agent It is used in diluted form as an intravenous infusion, its action ceasing within a very short time after administration is stopped. This method applies the same principle but is an improvement on the I V adrenalıne drip of Frankıs Evans (14)

Churchill-Davidson and Swan (15) have compared nor-adrenalıne and methedrine. It is interesting to note that they found both produce a bradycardia proportionate to the rise in blood pressure They comment that, while it is appropriate to use the physiological component whose absence caused the hypotension, "methedrine possesses the undeniable advantage that, in most instances, it produces the desired effect without the contmued attention of the physician"

3. Mephentermine (Wyamme Sulphate). For those who are impressed with the logical basis for the use of noi-adrenahne but who require a longer action, mephentermine has many advantages Its peripheral action and the duration of its effect, comparable with that of methedrine, without the excitatory action of the latter, render it a valuable agent.

In closing the subject of vasopressors, one might mention Inglis's recommendation that they be used for his middle gioup of hypotensives with normal heartrates

\section{Hypotension with Tachycardia}

Mention should be made of the 11 ( 11 per cent) cases in the hypotensive group who showed definite tachycardia While some of these may have been suffering from one or more of the common causes of "shock," mentioned above, there is always the odd case which does not respond to routine therapy The possible value of Ouabaine, or Strophanthın G, is mentioned in passing here Horton and Armstrong Davidson (16) have renewed interest in the use of this cardiac stımulant in shock and suggest, among other indications, its use to restore blood pressure with or without blood volume, replacement, "especially where there is peripheral vaso-constiction or tachycardia and when vasopressor drugs might then be contraindicated." It is felt that the number of occasions on which this agent would be of real value is small but that it should be part of the resuscitation armamentarıum Doses of $05 \mathrm{mgm}$ are recommended

\section{INFLUENCE OF Age ON INCIDENCE OF Hypotension}

This influence is difficult to assess in the present series and consequently mention has not been made of it before Twentv cases ( 11 per cent) from the whole series were below 40 years of age and might be assumed not to have 
developed peripheral vascular disease. Of these, 65 per cent (1.e., 13 out of 20) became hypotensive. In the larger, over 40 , group any or all of whom may have had peripheral vascular disease, 56 per cent (1.e, 88 out of 156) became hypotensive. It is doubtful whether one may draw any conclusion from this.

\section{Minor Vaginal SURCERY}

Comment here is with special reference to dilatation and curettage. Although the very large number of patients who have undergone this procedure and passed through the recovery room, have not been included in the present series, it is of interest that many have been noted to show hypotension with a relative bradycardia after operation There being no element of pain present, it is considered that these exemplify the pelvi-cardiac reflex mentioned above. This conclusion has been supported by their response to untravenous atropine.

\section{SUMMARY}

A series of 176 cases of major vaginal surgery have been followed through their immediate postoperative course and the incidence of hypotension in association with a relative bradycardia has been found to be high The possible aetiology and logical therapy have been discussed

\section{ACKNOWLEDGMENTS}

I am indebted to Dr J. McArthur for drawing my attention to the high inc1dence of hypotension following this type of surgery, to $\operatorname{Dr} R E$, Haist for his opinion on the physiology of the postural changes involved, and to the recovery room nurses of the Toronto General Hospital Prrvate Pavilion, whose very adequate records were of the maximal assistance

\section{RéSUMÉ}

On a surveillé les suites post-opératorres immédiates de 176 cas de chirurgie vaginale majeure, on a trouvé une incidence élevée d'hypotension associée à une bradycardie relative.

On a essayé de trouver les causes possibles de ces symptômes, les causes adjuvantes pourraient être une perte de sang, un changement de position, un temps opératoire prolongé, des manipulations brusques, un déséquilıbre de la chaleur et des électrolytes, une accumulation de $\mathrm{CO}_{2}$, une anoxie due à l'élımmation de $\mathrm{N}_{2} \mathrm{O}$ et enfin la douleur

Ces causes étudiées, Il reste quand même un groupe imposant que l'on ne peut expliquer Les causes d'hypotension, discutées plus haut, sont toutes associées à une tachycardıe On a supposé que ces patients souffrarent d'une dépression cardiovascularre à cause d'un réflexe pelvicardıaque perçu par les terminaisons nerveuses pelviennes sur le côté afférent et produısant, sur le còté efférent, une excitation vagale telle que décrite par Burstein (8), ces stimulı naissent au site de l'opération

Le traitement logique de ces conditions seralt de bloquer ce réflexe à différents niveaux:

(1) à la périphérie, sur le côté afférent, par une injection d'un agent anes- 
thésique local à longue action au site même de l'opération ou encore par une anesthésie régıonale à longue action.

(2) par une dépression centrale en donnant des agents analgésiques plus tôt et plus fréquemment.

(3) à la périphérıe, sur le côté eftérent, en donnant de l'atropine par vore intra-veineuse.

L'emploi d'agents ganglioplégıques tels que la procame ou la lignocame comme adjuvants d'une anesthésıe quı a pour but spécifique de b oquer le système nerveux autonome mérite d'être pris en considération.

L'emplo1 de vasopresseurs est un traitement purement symptomatique mars, au point de vue pratique, 1 l s'est avéré efficace en corrigeant l'hypotension dans 50 pour cent des cas de çe groupe de chutes de pression.

\section{REFERENCES}

1 SAunders, J W Lancet, 11286 (1952)

2 Case, E H \& Striles, I A Anosthesiology, 7 ' 29 ( 1946)

3 Cushny, A R Textbook of Pharmacology and Therapeutics 9th ed. London Churchill

4 Pappenheimer, J R \& Soto-Rivera, A. Am J Physiol., 152471 (1948)

5 Phimfose, W B Brit J Anaes, 26100 (1954)

6 Fink, B R Anesthesiology, 16511 ( 1955 )

7 Haist, R E Personal communication

8 Bunstein, C L Fundamental Consıderations in Andesthesid 2ncl ed, New York Macmillan

9 Inglis, J M Lancet, 2362 (1952).

10 Foulkes, J G Can Anaesth Soc J, 1 1 (1954)

11 Goldenbehg, M, Apgar, V, Deterling, R, \& Pines, K L J A.M A, 140.776 (1949)

12 Swan, H J C Brit Med J, 1 1003 (1952)

13 Churchilt-Davidson, H C, Wylie, W D, Miles, B E, \& De Wardener, H E Lancet, 2803 (1951)

14 Evans, F T Lancet, 1 15 (1944)

15 Churchill-Davidson, H C \& Swan, H J C Anaesthesid, 74 (1952)

16 Horton, J A C \& Armstronc.-Davmsion, M H Brit J. Anaesth, 27139 (1955) 